\title{
Antidepressent Effect of Two New Benzyl Derivatives from Wild Strawberry Fragaria vesca var. nubicola Lindl. ex Hook.f.
}

\author{
Sadia Naz¹, Umar Farooq ${ }^{1 *}$, Ajmal Khan ${ }^{1,2 *}$, Haroon Khan ${ }^{3}$, Nasiara Karim ${ }^{4}$, \\ Rizwana Sarwar ${ }^{1}$, Javid Hussain ${ }^{5}$ and Abdur Rauf 6
}

'Department of Chemistry, COMSATS Institute of Information Technology, Abbottabad, Pakistan, ${ }^{2}$ UoN Chair of Oman Medicinal Plants and Marine Products, University of Nizwa, Nizwa, Oman, ${ }^{3}$ Department of Pharmacy, Abdul Wali Khan University, Mardan, Pakistan, ${ }^{4}$ Department of Pharmacy, University of Malakand, Chakdara, Pakistan, ${ }^{5}$ Department of Biological Sciences and Chemistry, College of Arts and Sciences, University of Nizwa, Nizwa, Oman, ${ }^{6}$ Department of Chemistry, University of Swabi, Ambar, Pakistan

\section{OPEN ACCESS}

Edited by:

Banasri Hazra,

Jadavpur University, India

Reviewed by:

Sevser Sahpaz,

Lille 2 University of Health and Law,

France

Somiranjan Ghosh,

Howard University, United States

*Correspondence:

Umar Farooc

umarf@ciit.net.pk

Ajmal Khan

ajmalkhan@ciit.net.pk

Specialty section:

This article was submitted to

Ethnopharmacology,

a section of the journal

Frontiers in Pharmacology

Received: 23 March 2017

Accepted: 30 June 2017

Published: 25 July 2017

Citation:

Naz S, Faroog U, Khan A, Khan H, Karim N, Sarwar R, Hussain J and Rauf A (2017) Antidepressent Effect of Two New Benzyl Derivatives from Wild Strawberry Fragaria vesca var.

nubicola Lindl. ex Hook.f.

Front. Pharmacol. 8:469.

doi: 10.3389/fphar.2017.00469
Two new benzyl derivatives were isolated from ethyl acetate fraction of wild strawberry, Fragaria vesca var. nubicola Lindl. ex Hook.f. The structures of these compounds were elucidated to be 5-(4-hydroxy-3-methoxyphenethyl)-7-methoxy-2H-chromen-3-ol (1) and 5-(4-hydroxy-3-methoxyphenethyl)-4,7-dimethoxy-2H-chromen-3-ol (2) based on spectroscopic data through IR, UV, ${ }^{1} \mathrm{H}-\mathrm{NMR},{ }^{13} \mathrm{C}-\mathrm{NMR}$ along with two dimensional (2D) techniques $\mathrm{HMBC}, \mathrm{HMQC}$, and COSY. Both compounds $\mathbf{1}$ and $\mathbf{2}$ were studied in tail suspension and forced swim tests for antidepressant like effects. A significant dose dependent antidepressant like effect was observed by causing spontaneous anti-immobility at various test doses upon intraperitoneal administration.

Keywords: benzyl derivatives, Fragaria vesca var. nubicola, Rosaceae, antidepressant activity, anti-immobility

\section{INTRODUCTION}

Fragaria vesca var. nubicola Lindl. ex Hook.f.; commonly known as wild strawberry is synonym of Fragaria nubicola (Lindl. ex Hook.f.) Laciata. It is a perennial herb belonging to family Rosaceae that mostly grows along roadsides and in forests. The family Rosaceae comprises of 85 genera and nearly about 3000 species widely distributed in Europe and North America while represented by 27 genera and about 160 species in Pakistan (Stewart, 1972; Mabberley, 2008).

The vegetative parts of $F$. vesca var. nubicola has been used as stimulant, diuretic agent, detoxifying agent and for treatment of diarrhea (Neves et al., 2009). The achenes and thalamus parts of $F$. vesca has been reported to have high phenolic content and showed good antioxidant activity (Cheel et al., 2007). Literature revealed that fruits as well as whole plant of $F$. vesca var. nubicola has potential analgesic and anti-oxidant activity (Kanodia and Das, 2008; Kanodia et al., 2011). Similarly, the ethanolic extract of $F$. vesca var. nubicola possesses anti-convulsant activity and is effective for treatment of epilepsy (Patil et al., 2012).

Strawberry fruits reported to have phenolic compounds like ellagic acid, ellagic acidglycoside, coumaryl glycoside along with various anthocyanidin as their glycosides. The fruits are also reported to have anti-oxidant, anticancer, anti-inflammatory and anti-neurodegenerative properties (Hannum, 2004; Seeram et al., 2006). As previously reported the phytochemical investigation showed agrimoniin; an anti-tumor and antidiarrheal agent as major ellagitannins in F. vesca (Miyamoto et al., 1987; Vrhovsek et al., 2012). The roots of F. vesca var. nubicola are rich in proanthocyanidin (Vennat et al., 1986). Depression is one of serious disease prevailing 
all over the world affecting $13-20 \%$ population (Licinio and Wong, 1999). The discovery of new antidepressants is of utmost importance as significant proportion of patients develops resistance against medicines already available in market. Plants could be an effective approach for discovery of new antidepressant agents that can act via different mechanisms (Zhang, 2004).

Owing to its multiple traditional uses and strong phytochemical background of $F$. vesca var. nubicola, the current study was designed for isolation and characterization of bioactive secondary metabolites followed by their evaluation for antidepressant potential in various animal models.

\section{MATERIALS AND METHODS}

\section{Experimental Procedure}

The EI-MS and HR-EI-MS analysis were done using double focusing Varian MAT-312 spectrometer and Bruker AMX$500 \mathrm{MHz}$ spectrometer was used for ${ }^{1} \mathrm{H}-\mathrm{NMR}$ and ${ }^{13} \mathrm{C}-\mathrm{NMR}$ spectra. The chemical shift values were reported in $\mathrm{ppm}$ and scalar coupling in Hertz $(\mathrm{Hz})$ using tetramethyl silane (TMS) as internal standard. The TLC analysis was done by using pre coated silica gel plates while columns were packed using E. Merck 230-400 mesh and 70-230 mesh and UV active compounds were detected by using ceric sulfate in $10 \% \mathrm{H}_{2} \mathrm{SO}_{4}$ solution.

The IR and UV spectra were recorded through Hitachi JASCO-320-A and Hitachi UV-3200 spectrophotometer respectively.

\section{Plant Material}

The whole plant of F. vesca var. nubicola $(6 \mathrm{~kg})$ was collected from Hazara division of Khyber Pakhtunkhwa, Pakistan in May 2015 and a voucher specimen (no 8473) has been deposited in herbarium Department of Botany Postgraduate College, Abbottabad Pakistan.

\section{Extraction and Isolation}

The whole shade dried plant was ground into fine powder and extracted with methanol at room temperature and filtered thrice. The vacuum rotary evaporator was used to get crude extract from filtrate. The crude extract $(450 \mathrm{~g})$ was partitioned into four fractions as $n$-hexane (120 g), chloroform (75 g), ethyl acetate $(150 \mathrm{~g})$, and $n$-butanol $(65 \mathrm{~g})$. The ethyl acetate fraction was selected on the basis of TLC analysis and subjected to column chromatography by using $n$-hexane as gradient of ethyl acetate to $100 \%$ followed by methanol. Total 12 sub-fractions (A-L) were obtained and depending on TLC analysis four subfractions $(\mathrm{G}-\mathrm{J})$ were re-subjected to column chromatography to obtain compound 1 (12 mg) at $n$-hexane: ethyl acetate (40:60). Similarly compound $2(7.8 \mathrm{mg})$ was obtained from re-column chromatography of sub-fractions (D-F) at polarity of $n$-hexane: ethyl acetate (45:55) (Figure 1).

\section{Characterization of Compound 1}

A colorless oil; UV (MeOH) $\lambda_{\max } 222$ (2.9), 252 (3.6), 298 (3.9), 324 (4.6) nm; IR (KBr) $v_{\max } 3372,2920,1640,1610,1230$,
$1019 \mathrm{~cm}^{-1}$; EI-MS m/z: 328 [M] $^{+}$(100), 310 (80), 296 (60), 292 (62), 264 (50), 260 (39), 228 (71), 150 (30) and 120 (45); HREI-MS: $\mathrm{m} / \mathrm{z}\left[\mathrm{M}^{+}\right.$] Calcd. 328.1311 for Mol. formula $\mathrm{C}_{19} \mathrm{H}_{20} \mathrm{O}_{5}$; Observed 328.1305; ${ }^{1} \mathrm{H}$ NMR $\left(500 \mathrm{MHz}, \mathrm{CDCl}_{3}\right) \delta$ (ppm): 6.68 $(1 \mathrm{H}, \mathrm{d}=2.4 \mathrm{~Hz}, \mathrm{H}-2), 6.89(1 \mathrm{H}, \mathrm{d}=8.1 \mathrm{~Hz}, \mathrm{H}-5), 6.72(1 \mathrm{H}$, $\mathrm{dd}=8.1,2.4 \mathrm{~Hz}, \mathrm{H}-6), 2.76$ (2H, m, H-7), $2.94(2 \mathrm{H}, \mathrm{m}, \mathrm{H}-8), 6.54$ $(1 \mathrm{H}, \mathrm{d}=2.6 \mathrm{~Hz}, \mathrm{H}-10), 6.40(1 \mathrm{H}, \mathrm{d}=2.6 \mathrm{~Hz}, \mathrm{H}-12), 6.30(1 \mathrm{H}$, s, H-15), $4.28(1 \mathrm{H}, \mathrm{d}=15.6 \mathrm{~Hz}, \mathrm{H}-17), 3.80(1 \mathrm{H}, \mathrm{d}=15.6 \mathrm{~Hz}$, $\mathrm{H}-17), 3.74\left(3 \mathrm{H}, \mathrm{s}, 3-\mathrm{OCH}_{3}\right), 3.65\left(3 \mathrm{H}, \mathrm{s}, 11-\mathrm{OCH}_{3}\right) ;{ }^{13} \mathrm{C} \mathrm{NMR}$ $\left(125 \mathrm{MHz}_{\mathrm{CDCl}}\right) \delta$ (ppm): 137.2 (C-1), 119.2 (C-2), 149.9 (C3), 148.3 (C-4), 115.7 (C-5), 124.8 (C-6), 40.2 (C-7), 38.9 (C-8), 145.8 (C-9), 107.9 (C-10), 162.1 (C-11), 102.3 (C-12), 160.6 (C13), 109.7 (C-14), 104.4 (C-15), 150.6 (C-16), 64.3 (C-17), 58.4 $\left(3-\mathrm{OCH}_{3}\right), 56.4\left(11-\mathrm{OCH}_{3}\right)$.

\section{Characterization of Compound 2}

A colorless oil; UV (MeOH) $\lambda_{\max } 212$ (3.6), 240 (2.8), 296 (4.1), $310(3.9) \mathrm{nm}$; IR (KBr) $v_{\max } 3380,2960,1650,1230,1102 \mathrm{~cm}^{-1}$; EI-MS m/z: $358[\mathrm{M}]^{+}(100), 340(90), 326(75), 322$ (62), 294 (50), 290 (60), 264 (49), 258 (70), 226 (39), 148 (35), and 118 (43); HREI-MS: $\mathrm{m} / \mathrm{z}\left[\mathrm{M}^{+}\right.$] Calcd. 358.1416 for Mol. formula $\mathrm{C}_{20} \mathrm{H}_{22} \mathrm{O}_{6}$; Observed 358.1409; ${ }^{1} \mathrm{H}$ NMR (500 $\left.\mathrm{MHz}, \mathrm{CDCl}_{3}\right) \delta$ (ppm): 6.60 $(1 \mathrm{H}, \mathrm{d}=2.1 \mathrm{~Hz}, \mathrm{H}-2), 6.90(1 \mathrm{H}, \mathrm{d}=8.4 \mathrm{~Hz}, \mathrm{H}-5), 6.76(1 \mathrm{H}$, $\mathrm{dd}=8.4,2.1 \mathrm{~Hz}, \mathrm{H}-6), 2.62$ (2H, m, H-7), 2.82 (2H, m, H-8), 6.50 $(1 \mathrm{H}, \mathrm{d}=2.3 \mathrm{~Hz}, \mathrm{H}-10), 6.45(1 \mathrm{H}, \mathrm{d}=2.3 \mathrm{~Hz}, \mathrm{H}-12), 4.20(1 \mathrm{H}$, $\mathrm{d}=16.1 \mathrm{~Hz}, \mathrm{H}-17), 3.81(1 \mathrm{H}, \mathrm{d}=16.1 \mathrm{~Hz}, \mathrm{H}-17), 3.74(3 \mathrm{H}, \mathrm{s}, 3-$ $\left.\mathrm{OCH}_{3}\right), 3.59\left(3 \mathrm{H}, \mathrm{s}, 11-\mathrm{OCH}_{3}\right), 3.57\left(3 \mathrm{H}, \mathrm{s}, 15-\mathrm{OCH}_{3}\right) ;{ }^{13} \mathrm{C} \mathrm{NMR}$ (125 MHz, $\left.\mathrm{CDCl}_{3}\right) \delta(\mathrm{ppm}): 138.4(\mathrm{C}-1), 115.4$ (C-2), 150.1 (C-3), 144.6 (C-4), 117.7 (C-5), 123.8 (C-6), 37.4 (C-7), 36.8 (C-8), 146.3 (C-9), 111.6 (C-10), 162.4 (C-11), 99.6 (C-12), 159.3 (C-13), 107.8 (C-14), 116.4 (C-15), $136.6(\mathrm{C}-16), 60.9$ (C-17), $57.1\left(3-\mathrm{OCH}_{3}\right)$, $55.1\left(11-\mathrm{OCH}_{3}\right), 56.9\left(15-\mathrm{OCH}_{3}\right)$.

\section{Acute Toxicity Study of Compounds 1 and 2}

The acute toxicity of compounds $\mathbf{1}$ and $\mathbf{2}$ was determined by using swiss albino mice, according to the method described by Irwin (Irwin, 1968). The animals were divided into six groups $(n=9)$. One group served as a control and received vehicle orally. Briefly, compounds $\mathbf{1}$ and $\mathbf{2}$ each were administered at the dose level of 50,100, 200, and $300 \mathrm{mg} / \mathrm{kg}$ to each mouse orally. Each animal was subjected to various parameters including writhing, convulsions, aggressiveness, hypersensitivity, salivation, lacrimation, spontaneous activity, ataxia, and catalepsy $30 \mathrm{~min}$ prior to injection (baseline) and then at 0 (straight after injection), 30 and $60 \mathrm{~min}, 24,48$, and $72 \mathrm{~h}$ and 1 week after administration for any kind of behavioral, physical, and pharmacological toxic effects.

\section{Tail Suspension Test}

Mice were hung by their tail on the tail hanger using sticky tape for tail fixation, at approximately $1 \mathrm{~cm}$ from the end of the tail. The hanger was fixed in the black plastic box $(20 \mathrm{~cm} \times 20 \mathrm{~cm} \times 45 \mathrm{~cm})$ with the opening at the top front. The distance between the hanger and floor was approximately $40 \mathrm{~cm}$. The mouse was suspended in the air by its tail and the immobility 
TABLE 1 | ${ }^{1} \mathrm{H}$ NMR $\left(500 \mathrm{MHz}, \mathrm{CDCl}_{3}\right), \delta_{\mathrm{H}}$ in ppm and ${ }^{13} \mathrm{C} \mathrm{NMR}\left(125 \mathrm{MHz}, \mathrm{CDCl}_{3}\right), \delta_{\mathrm{C}}$ in ppm of compounds 1 and 2.

\begin{tabular}{|c|c|c|c|c|}
\hline \multirow[t]{3}{*}{ Position } & \multicolumn{2}{|c|}{ Compound 1} & \multicolumn{2}{|c|}{ Compound 2} \\
\hline & ${ }^{1} \mathrm{H}-\mathrm{NMR}$ & ${ }^{13} \mathrm{C}-\mathrm{NMR}$ & ${ }^{1} \mathrm{H}-\mathrm{NMR}$ & ${ }^{13} \mathrm{C}-\mathrm{NMR}$ \\
\hline & $\left(\delta_{\mathrm{H}} \mathrm{ppm}\right)$ and multiplicity & $\left(\delta_{\mathrm{c}} \mathrm{ppm}\right)$ & $\left(\delta_{\mathrm{H}} \mathrm{ppm}\right)$ & $\left(\delta_{\mathrm{c}} \mathrm{ppm}\right)$ \\
\hline 1 & - & 137.2 & - & 138.4 \\
\hline 2 & $6.68(1 \mathrm{H}, \mathrm{d}=2.4 \mathrm{~Hz})$ & 119.2 & $6.60(1 \mathrm{H}, \mathrm{d}=2.1 \mathrm{~Hz})$ & 115.4 \\
\hline 3 & - & 149.9 & - & 150.1 \\
\hline 4 & - & 148.3 & - & 144.6 \\
\hline 5 & $6.89(1 \mathrm{H}, \mathrm{d}=8.1 \mathrm{~Hz})$ & 115.7 & $6.90(1 \mathrm{H}, \mathrm{d}=8.4 \mathrm{~Hz})$ & 117.7 \\
\hline 6 & $6.72(1 \mathrm{H}, \mathrm{dd}=8.1,2.4 \mathrm{~Hz})$ & 124.8 & $6.76(1 \mathrm{H}, \mathrm{dd}=8.4,2.1 \mathrm{~Hz})$ & 123.8 \\
\hline 7 & $2.76(2 \mathrm{H}, \mathrm{m})$ & 40.2 & $2.62(2 \mathrm{H}, \mathrm{m})$ & 37.4 \\
\hline 8 & $2.94(2 \mathrm{H}, \mathrm{m})$ & 38.9 & $2.82(2 \mathrm{H}, \mathrm{m})$ & 36.8 \\
\hline 9 & - & 145.8 & - & 146.3 \\
\hline 10 & $6.54(1 \mathrm{H}, \mathrm{d}=2.6 \mathrm{~Hz})$ & 107.9 & $6.50(1 \mathrm{H}, \mathrm{d}=2.3 \mathrm{~Hz})$ & 111.6 \\
\hline 11 & - & 162.1 & - & 162.4 \\
\hline 12 & $6.40(1 \mathrm{H}, \mathrm{d}=2.6 \mathrm{~Hz})$ & 102.3 & $6.45(1 \mathrm{H}, \mathrm{d}=2.3 \mathrm{~Hz})$ & 99.6 \\
\hline 13 & - & 160.6 & - & 159.3 \\
\hline 14 & - & 109.7 & - & 107.8 \\
\hline 15 & $6.30(1 \mathrm{H}, \mathrm{s})$ & 104.4 & - & 116.4 \\
\hline 16 & - & 150.6 & - & 136.6 \\
\hline \multirow[t]{2}{*}{17} & $4.28(1 \mathrm{H}, \mathrm{d}=15.6 \mathrm{~Hz})$ & 64.3 & $4.20(1 \mathrm{H}, \mathrm{d}=16.1 \mathrm{~Hz})$ & 60.9 \\
\hline & $3.80(1 \mathrm{H}, \mathrm{d}=15.6 \mathrm{~Hz})$ & & $3.81(1 \mathrm{H}, \mathrm{d}=16.1 \mathrm{~Hz})$ & \\
\hline $3-\mathrm{OCH}_{3}$ & $3.74(3 \mathrm{H}, \mathrm{s})$ & 58.4 & $3.74(3 \mathrm{H}, \mathrm{s})$ & 57.1 \\
\hline $11-\mathrm{OCH}_{3}$ & $3.65(3 \mathrm{H}, \mathrm{s})$ & 56.4 & $3.59(3 \mathrm{H}, \mathrm{s})$ & 55.1 \\
\hline $15-\mathrm{OCH}_{3}$ & - & - & $3.57(3 \mathrm{H}, \mathrm{s})$ & 56.9 \\
\hline
\end{tabular}

time was recorded over a period of $5 \mathrm{~min}$. The duration of immobility was defined as the absence of all movements except for those required for respiration (Steru et al., 1985).

\section{Forced Swim Test}

For forced swim test in mice, the method reported by Porsolt et al. (1978) was adopted. Swim sessions of animal were performed in individual glass cylinders $(46 \mathrm{~cm}$ tall $\times 20 \mathrm{~cm}$ diameter) containing $30 \mathrm{~cm}$ of water at $24 \pm 1^{\circ} \mathrm{C}$. Following both swim sessions, mice were removed from the cylinders, dried with paper towels, and placed in heated cages for $15 \mathrm{~min}$ and then returned to their home cages. Various doses of test compounds $\mathbf{1}$ and $\mathbf{2}$ like 10,30 , and $100 \mathrm{mg} / \mathrm{kg}$ i.p. and standard Imipramine $(60 \mathrm{mg} / \mathrm{kg})$ were administered during two swim sessions: an initial 15-min pretest followed 14 days later by a 5 -min test.

\section{Research Ethics Committee Approval}

It is certified that the Departmental Research Ethics Committee (DREC) reviewed the National Research Program for Universities (NRPU) research grants application of the project entitled "Anxiolytic and Antidepressant Activities of Selected Natural product (Glycosides and Flavonoids)." The principal investigator of the project is Dr. Nasiara Karim, Assistant Professor, Department of Pharmacy, University of Malakand.

The Committee approves (DAEC/Pharm/2017/01) the study to be conducted in the present form, and expects to be inform about any revision in the protocol and subject/patient information/informed consent (where applicable).

\section{Statistical Analysis}

Data are presented as mean \pm SEM of six mice. A one-way factorial analysis of variance (ANOVA) followed by post hoc Dunnett's test for multiple comparisons was used to assess behavior in tests. The $P$-value $<0.05$ was considered as significant.

\section{RESULTS}

Two new benzyl derivatives have been isolated from ethyl acetate fraction of $F$. vesca var. nubicola through successive column chromatography, while characterization was made through various spectroscopic techniques and comparison with literature. The isolated compounds $\mathbf{1}$ and $\mathbf{2}$ exhibited significant antidepressant like effects in tail suspension and forced swim tests.

Compound 1 was isolated as colorless oil with molecular formula $\mathrm{C}_{19} \mathrm{H}_{20} \mathrm{O}_{5}$ as suggested by HR-EI-MS with highest molecular ion peak at $\mathrm{m} / \mathrm{z} 328.1305\left[\mathrm{M}^{+}\right]$and $\mathrm{m} / \mathrm{z}$ values obtained were $310,296,292,264,260,228,150$, and 120 . The UV spectrum showed absorption band at $\lambda_{\max } 222$ (2.9), 252 (3.6), 298 (3.9), 324 (4.6) and presence of various groups like hydroxyl group, alkane, alkene, aromatic moiety, and C-O were suggested by absorption bands in IR spectrum at $v_{\max } 3372,2920,1640$, 1610 , and 1230, respectively.

The ${ }^{1} \mathrm{H}$-NMR spectrum revealed the presence of five aromatic protons at chemical shift values of $\delta_{\mathrm{H}} 6.54(1 \mathrm{H}, \mathrm{d}=2.6 \mathrm{~Hz}, \mathrm{H}-10)$, $6.40(1 \mathrm{H}, \mathrm{d}=2.6 \mathrm{~Hz}, \mathrm{H}-12), 6.68(1 \mathrm{H}, \mathrm{d}=2.4 \mathrm{~Hz}, \mathrm{H}-2), 6.89(1 \mathrm{H}$, 
<smiles>[2H]C1Oc2cc(OC)cc(CCc3ccc(O)c(OC)c3)c2C=C1O</smiles>

1<smiles>COC1=C(O)COc2cc(OC)cc(CCc3ccc(O)c(OC)c3)c21</smiles>

2

FIGURE 1 | Structures of compounds 1 and 2 (Zhan et al., 2016).

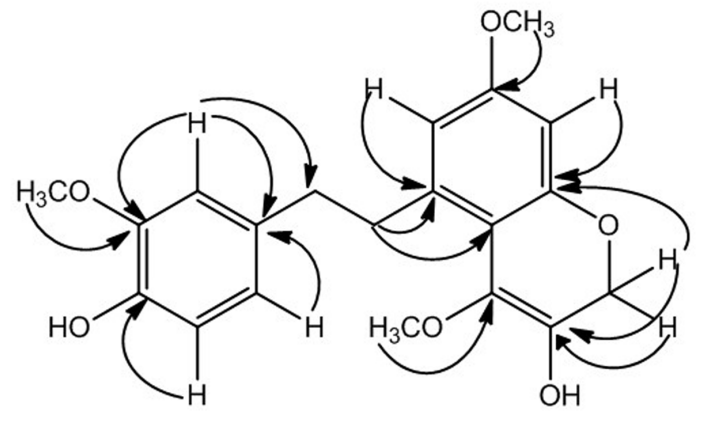

FIGURE 2 | Important HMBC $(\longrightarrow)$ correlations.

TABLE 2 | Effect of compounds on immobility time (sec) of mice using tail suspension test.

\begin{tabular}{llc}
\hline Treatment & Dose $\mathbf{( m g / k g )}$ & Immobility time (sec) \\
\hline Control & - & $175.5 \pm 10.5$ \\
Compound 1 & 10 & $170.4 \pm 11.5$ \\
& 30 & $140.5 \pm 5.3^{*}$ \\
Compound 2 & 100 & $110.35 \pm 8.2^{* *}$ \\
& 10 & $168.4 \pm 13.5$ \\
Imipramine & 30 & $130.3 \pm 7.5^{*}$ \\
& 100 & $105.5 \pm 10.3^{* *}$ \\
& 60 & $60.5 \pm 13.6^{* * *}$
\end{tabular}

All values are expressed in mean \pm SEM $(n=6)$. ${ }^{*} P<0.05,{ }^{*} P<0.01$, ${ }^{* * *} P<0.001$ compared to the vehicle group. Difference between groups were analyzed by analysis of variance (one-way ANOVA followed by Dunnett's test).

$\mathrm{d}=8.1 \mathrm{~Hz}, \mathrm{H}-5)$, and $6.72(1 \mathrm{H}, \mathrm{dd}=8.1,2.4 \mathrm{~Hz}, \mathrm{H}-6)$. Similarly two methylene proton signals appeared at $\delta_{\mathrm{H}} 2.76(2 \mathrm{H}, \mathrm{m}, \mathrm{H}-7)$ and $2.94(2 \mathrm{H}, \mathrm{m}, \mathrm{H}-8)$, while a methine proton resonated at $\delta_{\mathrm{H}}$ $6.30(1 \mathrm{H}, \mathrm{s}, \mathrm{H}-15)$ along with two oxidized protons at $\delta_{\mathrm{H}} 4.28$ and 3.80 showing germinal coupling with each other $(1 \mathrm{H}, \mathrm{d}=15.6 \mathrm{~Hz}$ each) as given in Table 1. The ${ }^{1} \mathrm{H}-\mathrm{NMR}$ spectrum also suggested the presence of two methoxy groups at $\delta_{\mathrm{H}} 3.74\left(3 \mathrm{H}, \mathrm{s},-\mathrm{OCH}_{3}\right)$ and $\delta_{\mathrm{H}} 3.65\left(3 \mathrm{H}, \mathrm{s}, \mathrm{OCH}_{3}\right)$.

The ${ }^{13} \mathrm{C}-\mathrm{NMR}$ and DEPT spectrum revealed the presence of nineteen 19 carbon atoms including two methyl, three methylene,
TABLE 3 | Effect of compounds on immobility time (sec) of mice using forced swimming test.

\begin{tabular}{llc}
\hline Treatment & Dose $(\mathbf{m g} / \mathbf{k g})$ & Immobility time $(\mathbf{s e c})$ \\
\hline Control & - & $185.5 \pm 12.5$ \\
Compound 1 & 10 & $178.5 \pm 10.6$ \\
& 30 & $115.5 \pm 11.3^{* *}$ \\
Compound 2 & 100 & $83.5 \pm 8.4^{* * *}$ \\
& 10 & $175.6 \pm 13.5$ \\
Imipramine & 30 & $140.4 \pm 7.8^{*}$ \\
& 100 & $71.9 \pm 10.5^{* * *}$ \\
& 60 & $76.5 \pm 14.6^{* * *}$
\end{tabular}

All values are expressed in mean \pm SEM $(n=6)$. ${ }^{*} P<0.05,{ }^{*} P<<0.01$, ${ }^{* * *} P<0.001$ compared to the vehicle group. Difference between groups were analyzed by analysis of variance (one-way ANOVA) followed by Dunnett's test.

six methine, and eight quaternary carbon atoms. Two methoxy carbons resonated at $\delta_{\mathrm{C}} 56.4(\mathrm{C}-11)$ and 58.4 (C-3) while three methylene carbons were observed at $\delta_{\mathrm{C}} 40.2$ (C-7), 38.9 (C-8), and 64.3 (C-17). ${ }^{13} \mathrm{C}$-NMR showed five aromatic methine carbon atoms at $\delta_{\mathrm{C}} 102.3(\mathrm{C}-12), 107.9$ (C-10), 119.2 (C-2), 115.7 (C-5), and $124.8(\mathrm{C}-6)$ with another methine carbon at $\delta_{\mathrm{C}} 104.4(\mathrm{C}-15)$ as given in Table 1 . The quaternary carbons resonated at $\delta_{\mathrm{C}} 149.9$ (C-3), 148.3 (C-4), 137.2 (C-1), 145.8 (C-9), 162.1 (C-11), 160.6 (C-13), 109.7 (C-14), and 150.6 (C-16).

The data of $\mathrm{HMBC}$ spectrum was quite supportive for accurate placement of substituents in compound 1. The HMBC correlation of methoxy protons at $\delta_{\mathrm{H}} 3.74$ showed strong correlation with C-3, C-4, and C-2 confirming its position at C-3 similarly second methoxy group $\left(\delta_{\mathrm{H}} 3.65\right)$ was placed at position C-11 showing HMBC correlation with C-10, C-11, and $\mathrm{C}-12$. The placement of two hydroxyl groups at C-4 and C-16 were established from HMBC correlations, like $\mathrm{H}-2\left(\delta_{\mathrm{H}} 6.68\right)$ and H-6 $\left(\delta_{\mathrm{H}} 6.72\right)$ showed connectivity with C-4 and correlation of $\mathrm{H}-17$ and $\mathrm{H}-15$ with $\mathrm{C}-16$ respectively. The methylene protons at position $\mathrm{C}-7$ showed strong $\mathrm{HMBC}$ correlations with C-1, C-2 and C-6, while protons at position C-8 showed HMBC correlations with C-9 and C-10 suggesting presence of bibenzyl group in compound $\mathbf{1}$ as depicted in Figure $\mathbf{2}$ (Zhan et al., 2016). The HMBC correlations of methylene protons 
at C-17 showed strong correlation with C-13, C-15, and C-16 while correlation of $\mathrm{H}-15$ with $\mathrm{C}-13, \mathrm{C}-14, \mathrm{C}-16$, and C-17 formed an oxygen heterocyclic ring as shown in Figure 1. The structure of compound 1 was suggested as 5-(4-hydroxy3-methoxyphenethyl)-7-methoxy-2H-chromen-3-ol on the basis of all spectral data and literature comparison (Zhan et al., 2016).

Compound 2 was isolated as colorless oil from ethyl acetate fraction of $F$. vesca var. nubicola. Its molecular formula was $\mathrm{C}_{20} \mathrm{H}_{22} \mathrm{O}_{6}$ as suggested by highest molecular ion peak at $\mathrm{m} / \mathrm{z}$ $358.1409\left[\mathrm{M}^{+}\right]$while other $\mathrm{m} / \mathrm{z}$ values were $340,326,322,294$, 290, 264, 258, 226, 148, and 118. The absorption bands in UV spectrum were obtained at $\lambda_{\max } 212$ (3.6), 240 (2.8), 296 (4.1), 310 (3.9) and IR spectrum showed absorption bands at $v_{\max }$ $3380,2960,1650,1610$, and 1230 suggesting presence of hydroxyl group, alkane, alkene, aromatic moiety, and $\mathrm{C}-\mathrm{O}$ respectively.

The ${ }^{1} \mathrm{H}-\mathrm{NMR}$ and ${ }^{13} \mathrm{C}-\mathrm{NMR}$ data of compound 2 is quite identical to compound $\mathbf{1}$. Compound $\mathbf{2}$ had one additional methoxy group which was evident from all spectral data. The ${ }^{1} \mathrm{H}$ NMR showed chemical shift value for three methoxy groups at $\delta_{\mathrm{H}} 3.74\left(3 \mathrm{H}, \mathrm{s}, \delta_{\mathrm{C}}=57.1\right)$ and $3.59\left(3 \mathrm{H}, \mathrm{s}, \delta_{\mathrm{C}}=55.1\right)$ at position C-3 and C-11 similar to compound 1 with additional methoxy group at position C-15 having chemical shift value of $\delta_{\mathrm{H}} 3.57(3 \mathrm{H}$, $\left.\mathrm{s}, \delta_{\mathrm{C}}=56.9\right)$. The ${ }^{1} \mathrm{H}-\mathrm{NMR}$ spectrum showed presence of five aromatic protons at $\delta_{\mathrm{H}} 6.60\left(1 \mathrm{H}, \mathrm{d}=2.1 \mathrm{~Hz}, \mathrm{H}-2, \delta_{\mathrm{C}}=115.4\right)$, $6.90\left(1 \mathrm{H}, \mathrm{d}=8.4 \mathrm{~Hz}, \mathrm{H}-5, \delta_{\mathrm{C}}=117.7\right), 6.76(1 \mathrm{H}, \mathrm{dd}=8.4,2.1 \mathrm{~Hz}$, $\left.\mathrm{H}-6, \delta_{\mathrm{C}}=123.8\right)$ for ring A along with $\delta_{\mathrm{H}} 6.50(1 \mathrm{H}, \mathrm{d}=2.3 \mathrm{~Hz}$, $\left.\mathrm{H}-10, \delta_{\mathrm{C}}=111.6\right)$ having meta coupling with proton at $\delta_{\mathrm{H}} 6.45$ $\left(1 \mathrm{H}, \mathrm{d}=2.3 \mathrm{~Hz}, \mathrm{H}-12, \delta_{\mathrm{C}}=99.6\right)$ at ring $\mathrm{B}$.

${ }^{13} \mathrm{C}-\mathrm{NMR}$ spectrum and DEPT showed presence of twenty carbon atoms including three methoxyl group, three methylene, five methine, and nine quaternary carbons given in Table $\mathbf{1}$. The HMBC correlations of substituents were quite identical to those for compound $\mathbf{1}$, the only difference observed was a methoxy group at position $\mathrm{C}-15$ showing $\mathrm{HMBC}$ connectivity of protons with C-15, C-16 and C-14. On the basis of all spectral data and literature comparison the structure established for compound 2 was 5-(4-hydroxy-3-methoxyphenethyl)-4,7dimethoxy-2H-chromen-3-ol.

\section{Acute Toxicity Tests}

Acute toxicity studies showed that the administration of compounds 1 and 2 at the dose level of $50-300 \mathrm{mg} / \mathrm{kg}$ did not produce any significant change in the behavior of the animals as observed by lack of convulsions, respiratory distress, writhing, changes to reflex activity, or mortality. A slight sedation was observed at $300 \mathrm{mg} / \mathrm{kg}$, however, the animals remained alert. At $24 \mathrm{~h}$ to 1 week, all animals seemed well with no observable changes in behavior or appearance. No deaths were observed up to 1 week of study.

\section{Effect in Tail Suspension Test}

The effects of both compounds $\mathbf{1}$ and $\mathbf{2}$ in tail suspension tested are shown in Table 2 . Both compounds $\mathbf{1}$ and $\mathbf{2}$ exhibited marked dose dependent antidepressant effects by reducing immobility time.

\section{Effect in Forced Swim Test}

Forced swim test is another useful and commonly used assay for the determination of antidepressant like effects of compounds (Mohseni et al., 2017; Sakhaee et al., 2017). Both compounds 1 and 2 showed dose dependent antidepressant effect as given in Table 3. Both isolated compounds caused significant immobility time and thus showed their potential as antidepressant.

\section{DISCUSSION}

The acute toxicity and behavioral test is mandatory for further detail studies. In our study both compounds were found safe with no behavior changes in the specified time, nor any mobility or mortality.

The TST and FST are reported to be the most commonly used predictive tests of antidepressant effects sensitive to the acute administration of antidepressant substances (Cryan et al., 2005). These behavioural tests are based on induction of immobility in rodents that face an inescapable situation and the antidepressant activity is indicated reduction in immobility time (Porsolt et al., 1977). In this study, compounds 1 and 2 displayed antidepressant like effects in both FST and TST. Although many antidepressant including monoamine oxidase inhibitors, tricyclics, selective serotonin reuptake inhibitors and selective noradrenaline reuptake inhibitors are available in the market for the treatment of various types of depressive disorders but even the first line antidepressant are facing many challenges in terms of unwanted effects (Kennedy, 2013; Johannessen et al., 2016).

The antidepressant like potential of natural isolated compounds is well-documented (Belozertseva et al., 2007; Pervez et al., 2016). Herbal therapies including the famous St. John's wort have been found effective in the treatment of various depressive disorders. There has been renewed interest recently for novel pharmacotherapy from medicinal plants and compounds isolated from plant extracts. It is assumed that they might follow a different mechanistic pathway and better pharmacokinetic profile and thus better patient compliance. The compounds $\mathbf{1}$ and $\mathbf{2}$ may serve as leads for the development of newer antidepressant agents from natural sources. However, further detail studies are needed to ascertain their clinical status.

\section{AUTHOR CONTRIBUTIONS}

AK and UF conceived and designed the study. SN performed isolation and $\mathrm{NK}$ performed in vivo studies. $\mathrm{JH}$ analyzed the data. UF and AK wrote the manuscript with inputs and comments from all co-authors. All authors have read and approved the final version of the manuscript.

\section{FUNDING}

We acknowledge Higher Education Commission (HEC) of Pakistan for financial support under NRPU programme No. 20-2798/NRPU. 


\section{REFERENCES}

Belozertseva, I., Kos, T., Popik, P., Danysz, W., and Bespalov, A. (2007). Antidepressant-like effects of mGluR1 and mGluR5 antagonists in the rat forced swim and the mouse tail suspension tests. Eur. Neuropsychopharmacol. 17, 172-179. doi: 10.1016/j.euroneuro.2006.03.002

Cheel, J., Theoduloz, C., Rodríguez, J. A., Caligari, P. D., and SchmedaHirschmann, G. (2007). Free radical scavenging activity and phenolic content in achenes and thalamus from Fragaria chiloensis ssp. chiloensis. F. vesca and F. $x$ ananassa cv. Chandler. Food Chem. 102, 36-44. doi: 10.1016/j.foodchem. 2006.04.036

Cryan, J. F., Mombereau, C., and Vassout, A. (2005). The tail suspension test as a model for assessing antidepressant activity: review of pharmacological and genetic studies in mice. Neurosci. Biobehav. Rev. 29, 571-625. doi: 10.1016/j. neubiorev.2005.03.009

Hannum, S. M. (2004). Potential impact of strawberries on human health: a review of the science. Crit. Rev. Food Sci. Nutr. 44, 1-17. doi: 10.1080/ 10408690490263756

Irwin, S. (1968). Comprehensive observational assessment: Ia. A systematic, quantitative procedure for assessing the behavioral and physiologic state of the mouse. Psychopharmacologia 13, 222-257. doi: 10.1007/BF004 01402

Johannessen, L., Henning, O., and Johannessen, S. I. (2016). Proconvulsant effects of antidepressants - What is the current evidence? Epilepsy Behav. 61, 287-291. doi: 10.1016/j.yebeh.2016.01.029

Kanodia, L., Borgohain, M., and Das, S. (2011). Effect of fruit extract of Fragaria vesca L. on experimentally induced inflammatory bowel disease in albino rats. Indian J. Pharmacol. 43, 18-21. doi: 10.4103/0253-7613.75660

Kanodia, L., and Das, S. (2008). A comparative study of analgesic property of whole plant and fruit extracts of Fragaria vesca in experimental animal models. Bangladesh J. Pharmacol. 4, 35-38. doi: 10.3329/bjp.v4i1.1049

Kennedy, S. H. (2013). A review of antidepressant therapy in primary care: current practices and future directions. Prim. Care Companion CNS Disord. 15:PCC.12r01420. doi: 10.4088/PCC.12r01420

Licinio, J., and Wong, M. (1999). The role of inflammatory mediators in the biology of major depression: central nervous system cytokines modulate the biological substrate of depressive symptoms, regulate stress-responsive systems, and contribute to neurotoxicity and neuroprotection. Mol. Psychiatry 4, 317327. doi: $10.1038 /$ sj.mp.4000586

Mabberley, D. J. (2008). Mabberley's Plant-Book: A Portable Dictionary of Plants, Their Classification and Uses. Cambridge: Cambridge University Press.

Miyamoto, K., Kishi, N., and Koshiura, R. (1987). Antitumor effect of agrimoniin, a tannin of Agrimonia pilosa Ledeb., on transplantable rodent tumors. Jpn. J. Pharmacol. 43, 187-195. doi: 10.1254/jjp.43.187

Mohseni, G., Ostadhadi, S., Imran-Khan, M., Norouzi-Javidan, A., Zolfaghari, S. Haddadi, N.-S., et al. (2017). Agmatine enhances the antidepressantlike effect of lithium in mouse forced swimming test through NMDA pathway. Biomed. Pharmacother. 88, 931-938. doi: 10.1016/j.biopha.2017. 01.119

Neves, J. M., Matos, C., Moutinho, C., Queiroz, G., and Gomes, L. R. (2009). Ethnopharmacological notes about ancient uses of medicinal plants in Trás-osMontes (northern of Portugal). J. Ethnopharmacol. 124, 270-283. doi: 10.1016/ j.jep.2009.04.041
Patil, M. V. K., Kandhare, A. D., Ghosh, P., and Bhise, S. D. (2012). Determination of role of GABA and nitric oxide in anticonvulsant activity of Fragaria vesca L. ethanolic extract in chemically induced epilepsy in laboratory animals. Orient. Pharm. Exp. Med. 12, 255-264. doi: 10.1007/s13596-012-0072-4

Pervez, S., Khan, H., and Pervaiz, A. (2016). Plant alkaloids as an emerging therapeutic alternative for the treatment of depression. Front. Pharmacol. 7:28. doi: 10.3389/fphar.2016.00028

Porsolt, R. D., Anton, G., Blavet, N., and Jalfre, M. (1978). Behavioural despair in rats: a new model sensitive to antidepressant treatments. Eur. J. Pharmacol. 47, 379-391. doi: 10.1016/0014-2999(78)90118-8

Porsolt, R. D., Bertin, A., and Jalfre, M. (1977). Behavioral despair in mice: a primary screening test for antidepressants. Arch. Int. Pharmacodyn. Ther. 229, 327-336.

Sakhaee, E., Ostadhadi, S., Khan, M. I., Yousefi, F., Norouzi-Javidan, A., Akbarian, R., et al. (2017). The role of NMDA receptor and nitric oxide/cyclic guanosine monophosphate pathway in the antidepressant-like effect of dextromethorphan in mice forced swimming test and tail suspension test. Biomed. Pharmacother. 85, 627-634. doi: 10.1016/j.biopha.2016.11.073

Seeram, N. P., Lee, R., Scheuller, H. S., and Heber, D. (2006). Identification of phenolic compounds in strawberries by liquid chromatography electrospray ionization mass spectroscopy. Food Chem. 97, 1-11. doi: 10.1016/j.foodchem. 2005.02.047

Steru, L., Chermat, R., Thierry, B., and Simon, P. (1985). The tail suspension test: a new method for screening antidepressants in mice. Psychopharmacology 85, 367-370. doi: 10.1007/BF00428203

Stewart, R. R. (1972). "An annotated catalogue of the vascular plants of West Pakistan and Kashmir," in Flora of West Pakistan, eds E. Nasir and S. I. Ali (Karachi: Fakhri Press), 1028.

Vennat, B., Pourrat, A., Texier, O., Pourrat, H., and Gaillard, J. (1986). Proanthocyanidins from the roots of Fragaria vesca. Phytochemistry 26, 261263. doi: 10.1016/S0031-9422(00)81524-1

Vrhovsek, U., Guella, G., Gasperotti, M., Pojer, E., Zancato, M., and Mattivi, F. (2012). Clarifying the identity of the main ellagitannin in the fruit of the strawberry, Fragaria vesca and Fragaria ananassa Duch. J. Agric. Food Chem. 60, 2507-2516. doi: 10.1021/jf2052256

Zhan, R., Zhang, Y., Chen, L., and Chen, Y. (2016). A new (propylphenyl) bibenzyl from Eria bambusifolia. Nat. Prod. Res. 30, 1740-1745. doi: 10.1080/14786419. 2015.1137572

Zhang, Z.-J. (2004). Therapeutic effects of herbal extracts and constituents in animal models of psychiatric disorders. Life Sci. 75, 1659-1699. doi: 10.1016/ j.lfs.2004.04.014

Conflict of Interest Statement: The authors declare that the research was conducted in the absence of any commercial or financial relationships that could be construed as a potential conflict of interest.

Copyright (c) 2017 Naz, Farooq, Khan, Khan, Karim, Sarwar, Hussain and Rauf. This is an open-access article distributed under the terms of the Creative Commons Attribution License (CC BY). The use, distribution or reproduction in other forums is permitted, provided the original author(s) or licensor are credited and that the original publication in this journal is cited, in accordance with accepted academic practice. No use, distribution or reproduction is permitted which does not comply with these terms. 